\title{
Dielectric characterization of microwave sintered lead zirconate titanate ceramics
}

\author{
Mayra D. Gonçalves ${ }^{a}$, Flavio L. Souza ${ }^{b}$, Elson Longo ${ }^{c}$, Edson R. Leite ${ }^{a}$, \\ Emerson R. Camargo ${ }^{\text {a,* }}$ \\ a LIEC-Department of Chemistry, UFSCar - Federal University of São Carlos. São Carlos, SP, Brazil \\ ${ }^{\mathrm{b}}$ UFABC - Federal University of ABC. Santo André, SP, Brazil \\ ${ }^{\mathrm{C}}$ Institute of Chemistry UNESP, São Paulo State University. Araraquara, SP, Brazil
}

\section{A R T I C L E I N F O}

Article history:

Received 10 March 2016

Received in revised form

7 May 2016

Accepted 6 June 2016

Available online 8 June 2016

Keywords:

PZT

Chemical synthesis

Dielectric response

Sintering

Ceramics

\begin{abstract}
A B S T R A C T
Highly reactive lead zirconate titanate powders (PZT) with different compositions were successfully synthesized by the oxidant-peroxo method (OPM) and used to prepare dense ceramic samples with composition near to the morphotropic phase boundary (MPB) sintered at $1000{ }^{\circ} \mathrm{C}$ for $2 \mathrm{~h}$ using a tubular conventional oven and a commercial microwave system. Crystalline phases were identified in the powder and ceramic samples by X-ray powder diffraction and FT-Raman spectroscopy at room temperature. The fractured surface of the ceramic sample showed a high degree of densification with fairly uniform grain sizes. Dielectric constants measured in the range from 30 to $500^{\circ} \mathrm{C}$ at different frequencies $(1,10$ and $100 \mathrm{kHz})$ indicated a normal ferroelectric behavior regardless of the sintering method. Samples sintered by a microwave radiation (MW) method and composition near to the MPB region showed a maximum dielectric constant of 17.911 and an anomalous high Curie temperature of $465{ }^{\circ} \mathrm{C}$.
\end{abstract}

(c) 2016 Elsevier Ltd and Techna Group S.r.l. All rights reserved.

\section{Introduction}

Polycrystalline lead zirconate titanate (PZT) has attracted considerable attention due to its technological importance and versatile properties, particularly in the so-called morphotropic phase boundary (MPB) region that occurs at nearly equal concentrations of $\mathrm{Ti}^{4+}$ and $\mathrm{Zr}^{4+}$. In this region, piezoelectric coefficients and dielectric constants exhibit an anomalously sharp maximum during the transition from Ti-rich tetragonal to Zr-rich rhombohedral phases [1]. The traditional route to obtain PZT involves reactions between metal oxides or carbonates at high temperatures [2,3]. However, this technique suffers from a number of uncertainties and drawbacks that result in severe stoichiometry deviations. The presence of impurities in raw materials, the lack of homogeneity due to poor mixing as well as a wide particle size distribution are major problems that led to the development of several alternative techniques to synthesize ceramic powders [4]. The oxidant peroxide method (OPM) is one of the most interesting wet-chemical routes for the synthesis of lead or bismuth based materials [5]. This route was named to as the oxidant peroxo method (OPM) and is based in the fundamental oxy-reduction reaction between lead (II) ions and several water-soluble titanium peroxo complexes.

\footnotetext{
* Corresponding author.

E-mail address: camargo@ufscar.br (E.R. Camargo).
}

This reaction results in an amorphous and reactive precipitate free of any common contaminants found in materials synthesized by other routes that use organic compounds to stabilize cations in solution [6-8]. Usually, residual carbon can be eliminated only after annealing at high temperatures, however it completely modifies the final properties and destroy the quality of powders synthesized by wet-chemical routes $[9,10]$.

Although powders synthesized by the OPM route show evident advantages regarding purity, reactivity, particle size and size distribution, many of the final properties of fine ceramics are determined by the sintering procedure. Conventionally, PZT ceramics require high temperatures exceeding $1250^{\circ} \mathrm{C}$, which is undesirable due to lead volatilization and a consequent loss in the composition that adversely affects the piezoelectric properties [11]. There has been a growing interest in the heating and sintering of ceramics by microwave radiation [12]. Since the first study demonstrating that PZT can be successfully prepared by the OPM route [13], efforts have been directed toward obtaining dense ceramics [14]. Apart from the extensive data available for PZT, little is known about the use of microwaves. Recently, Raju and Reddy [15] reported the influence of microwave sintering on the structural and dielectric properties of lead zirconate titanate using very reactive powders synthesized by the citrate method with a composition around the MPB. Ramana et al. [16] compared microwave sintering with the conventional method using PZT powders synthesized by the solid state reaction and concluded that microwave 
radiation can improve the densification at lower temperatures and can also reduce the soaking time. In this process, heat is generated internally within the material instead of originating from external sources and is responsible for a unique microstructure and uniformity [17]. It should be noted that all these studies indicated that microwave sintering is a promising technique to obtain highly dense ceramics with superior dielectric behavior.

In this study, we are presenting the synthesis of lead zirconate titanate powders by the OPM route and the electrical characterization of dense ceramic bodies with composition near to the MPB region sintered by conventional and microwave processing, which resulted in ceramics with a maximum dielectric constant of 17.911 and an anomalous high Curie temperature of $465^{\circ} \mathrm{C}$.

\section{Experimental}

\subsection{Synthesis and sintering}

All chemical reagents were used as received. Three nominal compositions of $\mathrm{Pb}\left(\mathrm{Zr}_{1-\mathrm{x}} \mathrm{Ti}_{\mathrm{x}}\right) \mathrm{O}_{3} \quad(\mathrm{x}=0.20,0.48$ and 0.80 , with samples referred to as PZTX where " $X$ " indicates the percentage of titanium) were prepared by the OPM route [5]. In a typical procedure, $1 \mathrm{~g}(0.02 \mathrm{~mol})$ of titanium metal powder (99.7\%, Aldrich, Germany) was added into a mixture of $80 \mathrm{~mL}$ of hydrogen peroxide (analytical grade, Synth, Brazil) and $20 \mathrm{~mL}$ of aqueous ammonia solution (analytical grade, Synth, Brazil). This solution was left in an ice-water bath for approximately $5 \mathrm{~h}$, resulting in a yellow transparent aqueous solution of soluble peroxytitanate $\left[\mathrm{Ti}(\mathrm{OH})_{3} \mathrm{O}_{2}\right]^{-}$ions. Zirconyl (IV) nitrate hydrate $\left(\mathrm{ZrO}\left(\mathrm{NO}_{3}\right)_{2} \cdot \mathrm{H}_{2} \mathrm{O}\right.$, 99.99\%, Aldrich, Germany) was previously submitted to gravimetric analysis by heat treatment at $900{ }^{\circ} \mathrm{C}$ for $2 \mathrm{~h}$ to estimate the exact molar quantity of zirconium per gram. The $\mathrm{ZrO}\left(\mathrm{NO}_{3}\right)_{2} \cdot \mathrm{H}_{2} \mathrm{O}$ was weighed and added into $100 \mathrm{~mL}$ of deionized water and lead nitrate (99.9\%, Aldrich, Germany) was added to complete the desired stoichiometric molar ratio. Finally, the solution of zirconium and lead nitrates was slowly dripped into the peroxytitanate solution under stirring, resulting in a vigorous evolution of gas. The system lost its yellow color and an orange precipitate formed immediately exothermically. This precipitate was filtered and washed with diluted ammonia to eliminate nitrate ions. The washed amorphous precipitate was dried at $50{ }^{\circ} \mathrm{C}$ for $5 \mathrm{~h}$ and ground using a mortar. Amounts of $0.20 \mathrm{~g}$ of the amorphous powder were calcined between 400 and $900{ }^{\circ} \mathrm{C}$ for $2 \mathrm{~h}$ using a heating rate of $10{ }^{\circ} \mathrm{C} \mathrm{min}^{-1}$ in closed alumina boats. Disks ( $10 \mathrm{~mm}$ diameter and $1.1 \mathrm{~mm}$ thick) were prepared with $0.50 \mathrm{~g}$ of $\mathrm{Pb}\left(\mathrm{Zr}_{1-\mathrm{x}} \mathrm{Ti}_{\mathrm{x}}\right) \mathrm{O}_{3}$ powders calcined at $700{ }^{\circ} \mathrm{C}$ for $2 \mathrm{~h}$ and isostatically pressed with a load of $30 \mathrm{t}$ for $1 \mathrm{~min}$. After pressing, the disks were sintered at $1000^{\circ} \mathrm{C}$ for $2 \mathrm{~h}$ using (i) a tubular oven with a heating rate of $10^{\circ} \mathrm{C} \mathrm{min}-1$ and (ii) a microwave oven with heating rate of $25^{\circ} \mathrm{C} \mathrm{min}{ }^{-1}$. To avoid lead volatilization, samples were sintered using closed zirconia crucibles, keeping them immersed in a powder with the same composition of the sample. The relative densities of sintered samples were measured using the Archimedes method.

\subsection{Characterization}

Amorphous precursors (10 mg) were analyzed by differential scanning calorimetry (Netzsch DSC 204 Phoenix) in the range from -100 to $550{ }^{\circ} \mathrm{C}$ at heating rate of $10^{\circ} \mathrm{C} \mathrm{min}^{-1}$ under a nitrogen atmosphere. The amorphous precursor, heat-treated powders and all sintered samples were characterized at room temperature by Fourier transform Raman spectroscopy (FT-Raman, Bruker RFS $100 / \mathrm{S}$ ) using the $1064 \mathrm{~nm}$ line of a yttrium aluminum garnet laser. These samples were also characterized by X-ray diffraction (XRD) using $\mathrm{Cu} \mathrm{K \alpha}$ radiation (Rigaku D/MAX 200 with a rotary anode operating at $150 \mathrm{kV}$ and $40 \mathrm{~mA}$ ) in the $2 \theta$ range from $5^{\circ}$ to $75^{\circ}$ with a step scan of $0.02^{\circ}$. The specific area of PZT powder heattreated at $700{ }^{\circ} \mathrm{C}$ for $2 \mathrm{~h}$ was determined by BET isotherms using a Micromeritics ASAP 2000. The powder morphology was verified by transmission electron microscopy (TEM, Philips CM200), and the cleaved sintered ceramics were characterized by high-resolution field emission scanning electron microscopy (FE-SEM, Zeiss Supra 35 at $2 \mathrm{kV}$ ). The fractured surface composition was determined by energy dispersive X-ray (EDX) spectroscopy (FEI XL30 FEG with an Oxford Instruments - Link ISIS 300 detector). For the electrical measurements, gold contacts were sputtered on two opposite faces of the disks, and the dielectric constant $\left(\varepsilon^{\prime}\right)$ of the sintered samples was measured in the temperature range from 30 to $500{ }^{\circ} \mathrm{C}$ using a Keithley 3330 (LCZ) meter at different frequencies $(1,10$, and $100 \mathrm{kHz})$. Two different heating rates were evaluated $\left(1\right.$ and $5{ }^{\circ} \mathrm{C} \mathrm{min}^{-1}$ ) and the $1{ }^{\circ} \mathrm{Cmin}^{-1}$ was choose to carry out to measure the dielectric constant. In order to guarantee the furnace temperature stability, each value of the dielectric constant was collected only after leaving the sample for $30 \mathrm{~min}$ in each temperature.

\section{Results and discussion}

Although PZT is widely investigated, there are only a few studies about PZT powders synthesized by the OPM route $[5,13]$. Despite this fact, it is well known that the amorphous precipitate is rich is peroxide groups that release a large amount of oxygen gas during their exothermic decomposition [5-8,13,14,18]. For this reason, sintered ceramics prepared directly from the amorphous precipitate are fragile. On the other hand, powders calcined at temperatures higher than the peroxide decomposition are highly reactive $[5,8,14]$. To find the best calcination temperature, we evaluated the PZT powders calcined at temperatures from 400 to $900{ }^{\circ} \mathrm{C}$. Due the highly reactivity, powders calcined at higher temperatures revealed large agglomerates partially sintered. Powders calcined up to $600{ }^{\circ} \mathrm{C}$ were poorly crystalline and revealed a mixture of tetragonal and rhombohedral phases that

Table 1

Lattice parameters, tetragonality factor (c/a), and unit cell volume for $\mathrm{Pb}\left(\mathrm{Zr}_{1-\mathrm{x}} \mathrm{Ti}_{\mathrm{x}}\right) \mathrm{O}_{3}$ with $\mathrm{x}=0.20 ; 0.48$ and 0.80 powders calcined at 700 to $900{ }^{\circ} \mathrm{C}$ for $2 \mathrm{~h}$.

\begin{tabular}{|c|c|c|c|c|c|c|c|}
\hline Composition & Geometry & Heat treatment $\left({ }^{\circ} \mathrm{C}\right)$ & $\mathbf{A}=\mathbf{b}(\check{\mathrm{A}})$ & $\mathbf{c}(\breve{A})$ & $\mathbf{V}\left(\breve{A}^{3}\right)$ & $\mathbf{c} / \mathbf{a}$ & File JCPDS \\
\hline \multirow[t]{3}{*}{ PZT80 } & Tetragonal & 900 & $3.9597 \pm 0.0001$ & $4.1314 \pm 0.0001$ & $64.776 \pm 0.003$ & 1.043 & \\
\hline & & 800 & $3.9529 \pm 0.0001$ & $4.1347 \pm 0.0001$ & $64.606 \pm 0.003$ & 1.046 & $6-452$ \\
\hline & & 700 & $3.9354 \pm 0.0001$ & $4.1437 \pm 0.0001$ & $64.174 \pm 0.003$ & 1.053 & \\
\hline \multirow[t]{3}{*}{ PZT48 } & Tetragonal & 900 & $4.0473 \pm 0.0002$ & $4.1342 \pm 0.0003$ & $67.720 \pm 0.007$ & 1.021 & \\
\hline & & 800 & $4.0193 \pm 0.0002$ & $4.1243 \pm 0.0003$ & $66.626 \pm 0.008$ & 1.026 & $50-346$ \\
\hline & & 700 & $4.0022 \pm 0.0002$ & $4.1057 \pm 0.0003$ & $65.762 \pm 0.007$ & 1.026 & \\
\hline \multirow[t]{3}{*}{ PZT20 } & Rhombohedral & 900 & $5.2529 \pm 0.0003$ & $13.912 \pm 0.0013$ & $332.45 \pm 0.04$ & - & \\
\hline & & 800 & $5.2541 \pm 0.0003$ & $13.909 \pm 0.001$ & $332.53 \pm 0.04$ & - & 89-1276 \\
\hline & & 700 & $5.2544 \pm 0.0003$ & $13.907 \pm 0.001$ & $332.52 \pm 0.04$ & - & \\
\hline
\end{tabular}




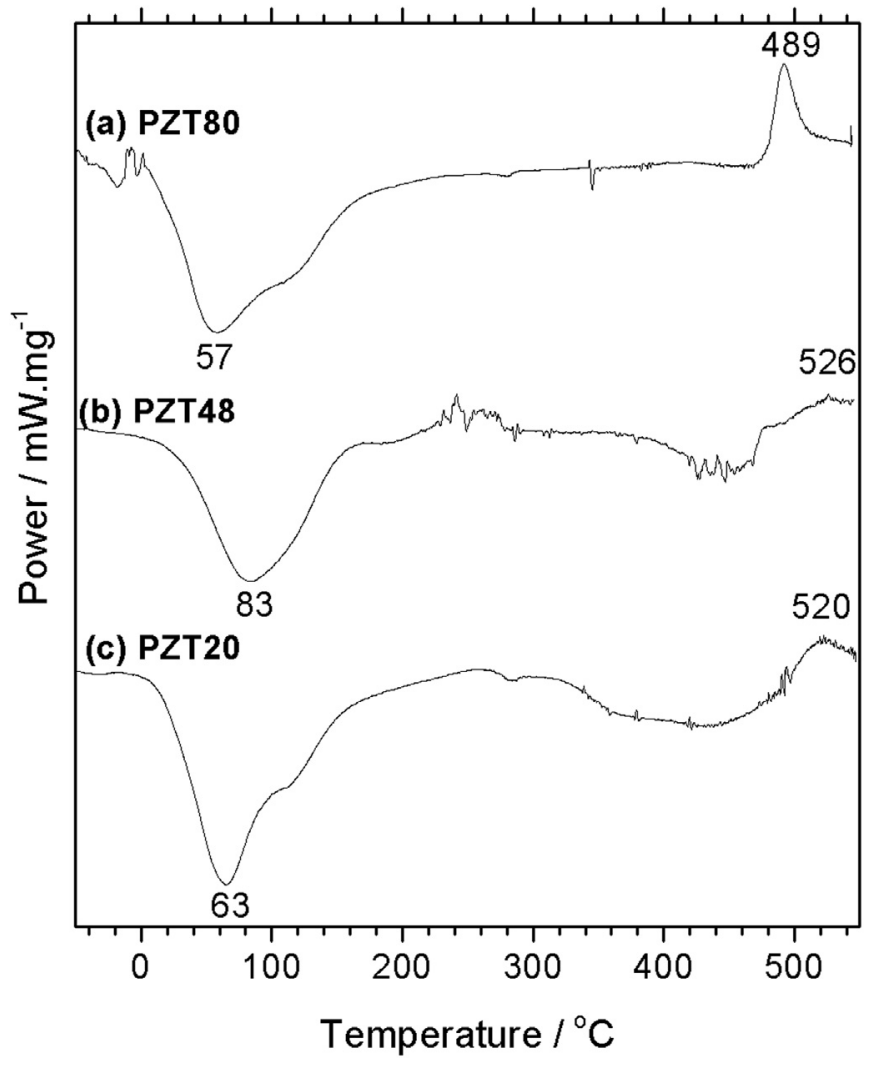

Fig. 1. DSC heating curves of (a) PZT80, (b) PZT48 and (c) PZT20.

could result in unsatisfactory sintering. Table 1 shows the cell parameters of the samples calcined at $700{ }^{\circ} \mathrm{C}$ and higher temperatures calculated using the Unitcell free software. This table revels single-phase samples with well-defined cell parameters with few differences between the values of powders calcined at $700{ }^{\circ} \mathrm{C}$ and $900{ }^{\circ} \mathrm{C}$, suggesting samples of high crystallinity.

\subsection{Powder characterization}

Powders of PZT synthesized by the OPM route are completely free from halides or carbon, which represents an advantage over other wet chemical routes used to obtain reactive powders. Fig. 1 shows DSC heating curves of different PZT precursors with (a) the tetragonal PZT80 titanium-rich composition with $80 \%$ in mol of titanium, (b) the PZT48 sample at MPB, and (c) the rhombohedral PZT20 zirconium-rich precursor. The exothermic peaks observed at high temperatures in the curves (a) and (c) are related to tetragonal-to-cubic phase transition at $489^{\circ} \mathrm{C}$ for PZT80, and to rhombohedral-to-cubic transition at $520^{\circ} \mathrm{C}$ for PZT20, respectively. All samples showed a broad and intense endothermic peak between 10 and $120^{\circ} \mathrm{C}$, which is associated with two important events that occur almost simultaneously in the crystallization step. During the synthesis of PZT by the OPM method, titanium and zirconium peroxo complexes in solution oxidize lead (II) at high $\mathrm{pH}$ to lead (IV), precipitating an amorphous and stoichiometric precursor that is unstable at high temperatures. When this precursor is annealed, lead (IV) is reduced to lead (II) again, releasing oxygen gas. At the same time, titanium and zirconium octahedra that were already formed during the precipitation are reorganized to form the desired crystalline phase [5]. All these processes are chemically complex and can be related to the endothermic peak identified in the DSC curves. It is interesting to note that during the synthesis of pure lead titanate [18], these events occurred between 440 and $490{ }^{\circ} \mathrm{C}$ when the DSC heating curve started at

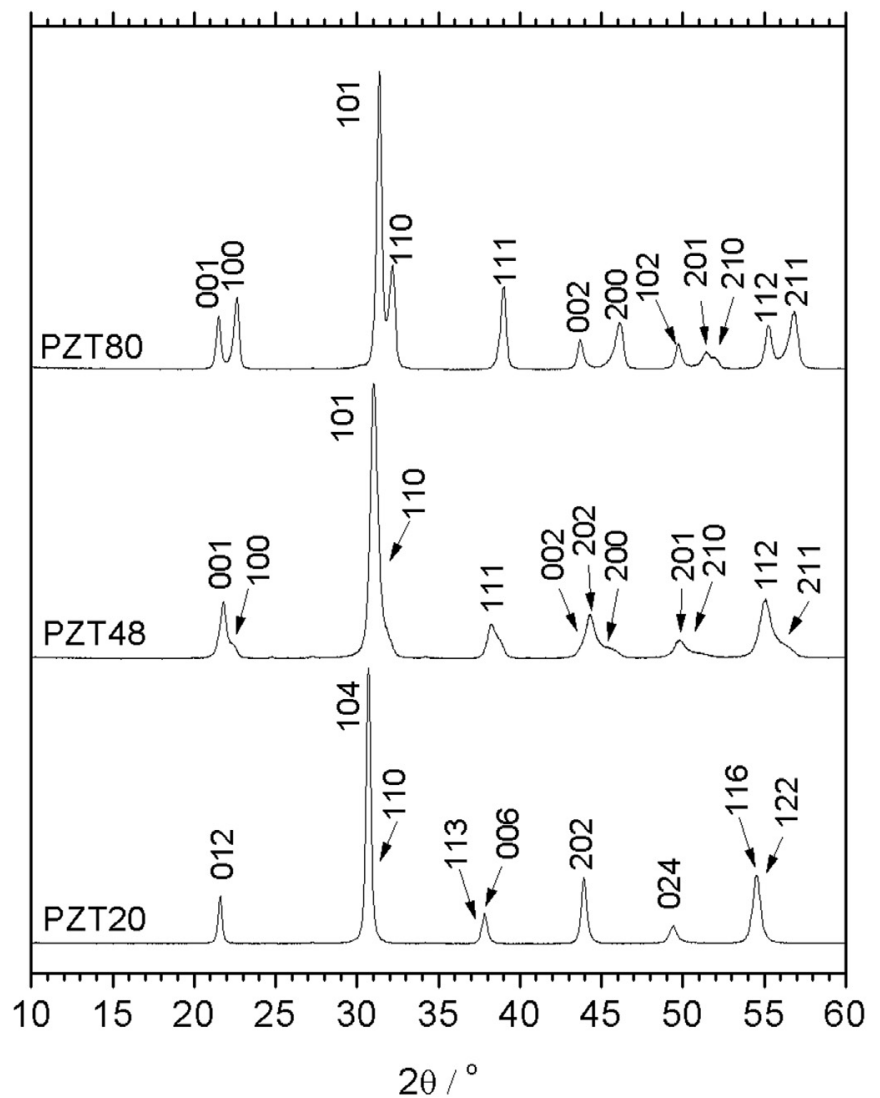

Fig. 2. XRD patterns of PZT powders with different compositions annealed at $700{ }^{\circ} \mathrm{C}$ for $2 \mathrm{~h}$.

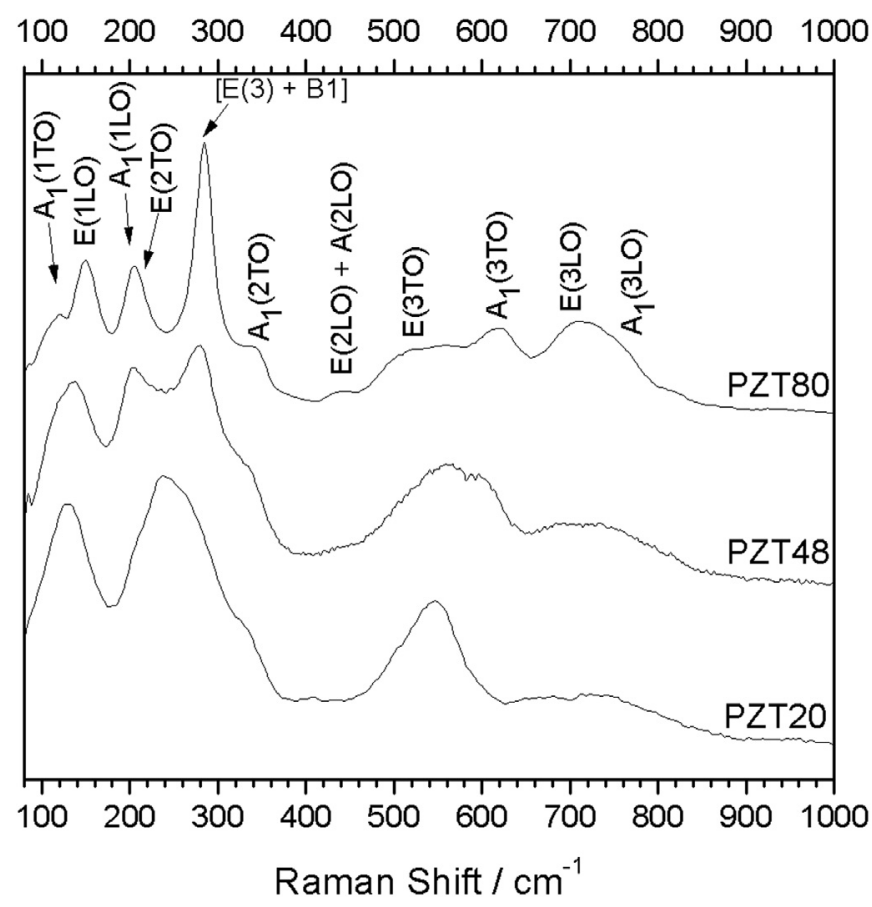

Fig. 3. Raman spectra of PZT powders with different compositions annealed at $700{ }^{\circ} \mathrm{C}$ for $2 \mathrm{~h}$

$50{ }^{\circ} \mathrm{C}$, which is almost $400{ }^{\circ} \mathrm{C}$ higher than the curves of Fig. 1 initiated at $-100{ }^{\circ} \mathrm{C}$, indicating that the crystallization process is dependent on the processing history of the precursor [19].

Precursors were annealed at $700{ }^{\circ} \mathrm{C}$ for $2 \mathrm{~h}$ and characterized by XRD (Fig. 2) and Raman spectroscopy (Fig. 3). This heat 
Table 2

BET surface area $\left(\mathrm{A}_{\mathrm{BET}}\right)$ and calculated diameter of the powders heat treated at $700{ }^{\circ} \mathrm{C}$ for $2 \mathrm{~h}$

\begin{tabular}{llll}
\hline Composition & $\mathbf{A}_{\text {BET }}\left(\mathbf{m} / \mathbf{g}^{\mathbf{3}}\right)$ & Diameter $(\mathbf{n m})$ & Synthetic method \\
\hline PZT80 & $9.60 \pm 0.2$ & 72.5 & OPM \\
PZT48 & $12.4 \pm 0.3$ & 58.8 & OPM \\
PZT20 & $8.50 \pm 0.2$ & 69.7 & OPM \\
PZT50 & 3.00 & & Polymeric precursor [22] \\
PZT48 & 4.20 & & C/N autocombustion [23] \\
PZT48 & 3.21 & & Hydrothermal [24] \\
PZT48 & 3.00 & & Modified Sol-gel [25] \\
\hline
\end{tabular}

treatment ensured that all powders were completely crystallized, which is fundamental to prepare dense sintered samples from OPM powders. When non-crystallized OPM precursors are directly used to prepare ceramic bodies, the oxygen gas released during the crystallization process increases the internal pressure, which creates pores or cavities inside the ceramic that results in fragile and non-densified samples not suitable for dielectric applications. The XRD pattern of annealed PZT80 powder in Fig. 2 shows the tetragonal structure with all peaks identified and assigned (JCPDF 6-542) while the PZT20 pattern shows the expected rhombohedral structure of compositions rich in zirconium (JCPDF 89-1276). On the other hand, the PZT48 pattern of the sample at MPB composition shows a mixture of tetragonal and rhombohedral phases (JCPDF 50-432) that is responsible for the anomalously sharp high piezoelectric and dielectric properties exhibited by samples at this composition [20,21]. This mixture of phases is much more evident in the Fig. 3 where the Raman spectrum of PZT48 shows a mixture of phases with peaks from both tetragonal and rhombohedral structures. The spectrum of PZT80 shows all bands related to the tetragonal phase and the PZT20 spectrum is typical of a rhombohedral structure, in good agreement with the XRD results of Fig. 2.

Table 2 shows the BET specific surface area of PZT powders synthesized by the OPM route heat treated at $700{ }^{\circ} \mathrm{C}$ for $2 \mathrm{~h}$. For comparison, the surface areas of some PZT powders synthesized by different wet-chemical techniques are also shown [22-25]. It is well known that higher surface area results in powders with higher sinterability which indicates that the OPM route forms particles much more reactive than that obtained by others wetchemical routes such as autocombustion [22], polymeric precursor [23], hydrothermal processing [24] or some modified sol-gel route [25], for reasons related to intrinsic characteristics of each method. In the case of autocombustion and polymeric precursor methods, there is a large amount of energy released during the synthesis that leads particles to agglomerate and be partially sintered which reduces the total surface area. In both cases, the amount of organic material plays an important role. In the case of hydrothermal processing, particles in suspension tend to form complicated agglomerated structures, which decrease the contact area in the
Table 3

Measured weight loss, shrinkage and relative densities calculated by Archimedes method of PZT ceramic bodies sintered by conventional (CO) and microwave (MW)

\begin{tabular}{lllll}
\hline Composition & Oven & $\begin{array}{l}\text { Weight loss (\%) } \\
\pm \mathbf{0 . 0 1}\end{array}$ & $\begin{array}{l}\text { Shrinkage (\%) } \\
\pm \mathbf{1}\end{array}$ & $\begin{array}{l}\text { Relative density } \\
(\%) \pm \mathbf{0 . 1}\end{array}$ \\
\hline \multirow{2}{*}{ PZT80 } & CO & 0.87 & 42 & 92.2 \\
& MW & 0.85 & 35 & 94.3 \\
PZT48 & CO & 0.54 & 47 & 99.2 \\
& MW & 0.58 & 47 & 99.8 \\
PZT20 & CO & 0.30 & 34 & 80.1 \\
& MW & 0.34 & 31 & 78.6 \\
\hline
\end{tabular}

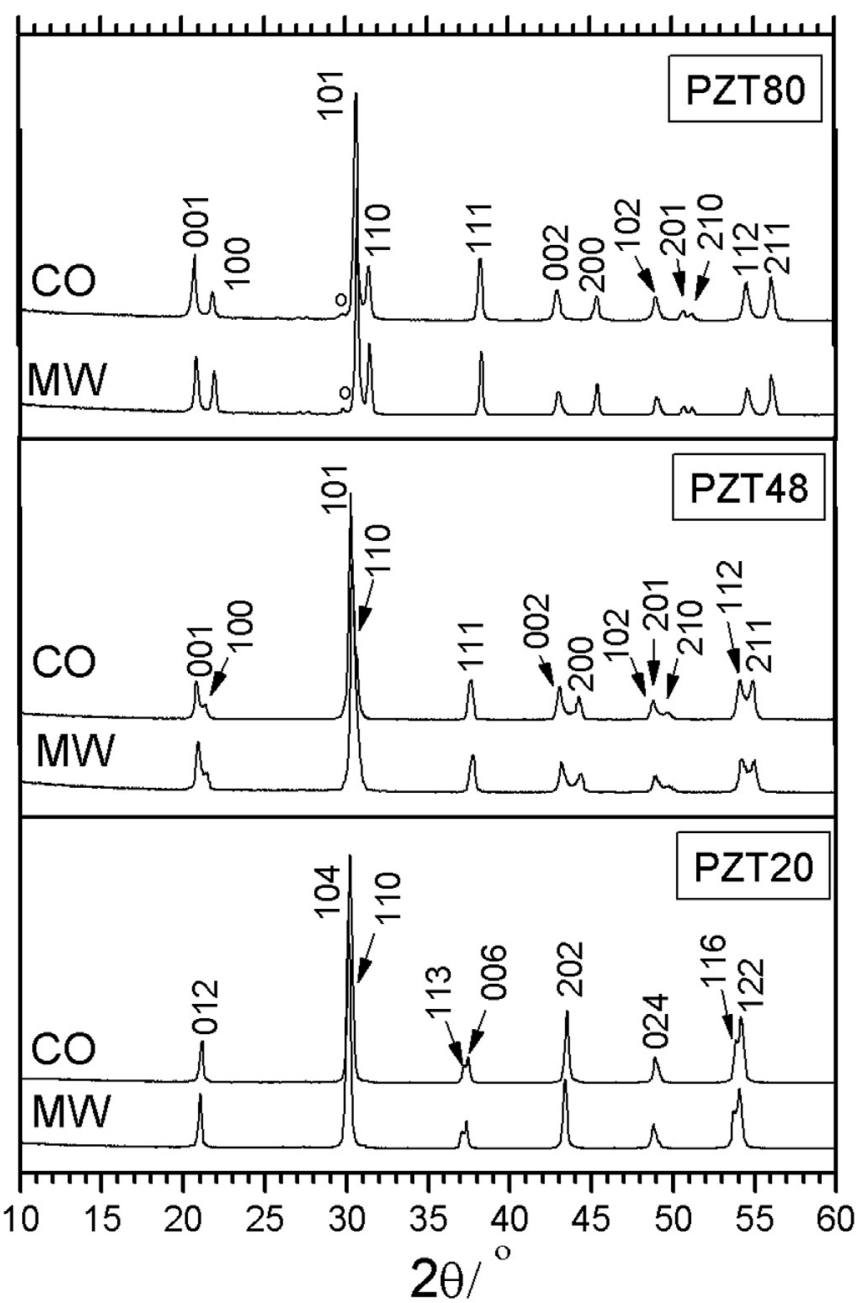

Fig. 5. DRX patterns of PZT ceramics with different compositions sintered at $1000{ }^{\circ} \mathrm{C}$ for $2 \mathrm{~h}$ using conventional oven (CO) and microwave processing (MW).
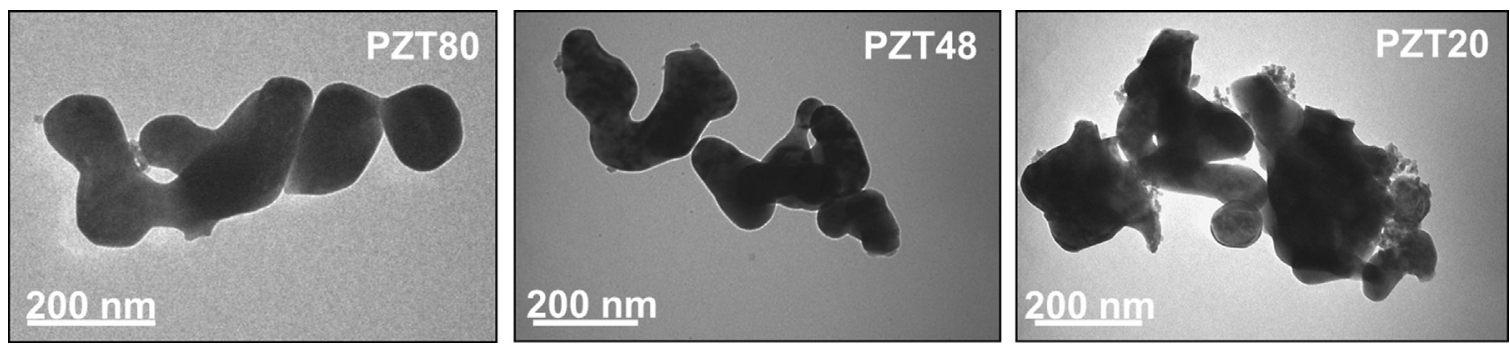

Fig. 4. TEM images of PZT powders with different compositions annealed at $700{ }^{\circ} \mathrm{C}$ for $2 \mathrm{~h}$. 
Table 4

Comparison between nominal and real molar compositions obtained by EDS measurements of the PZT ceramic bodies.

\begin{tabular}{lll}
\hline & Nominal molar composition (\%) & Real molar composition (\%) \\
\hline Sample & $\mathbf{P b} / \mathbf{Z r} / \mathbf{T i}$ & $\mathbf{P b} / \mathbf{Z r} / \mathbf{T i}$ \\
PZT80 & $100 / 20 / 80$ & $92 / 18 / 82$ \\
PZT48 & $100 / 52 / 48$ & $94 / 48 / 52$ \\
PZT20 & $100 / 80 / 20$ & $100 / 79 / 21$ \\
\hline
\end{tabular}

interface between the oxide and the solvent. Finally, powders synthesized by sol-gel routes are so reactive that the surface area decreased from $25 \mathrm{~m}^{2} \mathrm{~g}^{-1}$ to $3,5 \mathrm{~m}^{2} \mathrm{~g}^{-1}$ when PZT48 powders were calcined at low temperatures and short times [25].

Images of TEM support the extensive reactivity of particles synthesized by the OPM route and show that the temperature of $700^{\circ} \mathrm{C}$ is sufficiently high to form strong agglomerates independent of the composition (it is possible to see in Fig. 4 agglomerates partially sintered with the presence of necks between the particles). Although the particles are somewhat aggregated, the contrast in the TEM images indicates that each particle has a diameter in the range from 60 to $80 \mathrm{~nm}$ and that each agglomerate is formed of several particles.

\subsection{Ceramic characterization}

In a previous study about $\mathrm{Pb}\left(\mathrm{Zr}_{0.5} \mathrm{Ti}_{0.5}\right) \mathrm{O}_{3}$ prepared by the OPM route [26], it was demonstrated that samples sintered by conventional route resulted in dense ceramics with dielectric properties consistent with the values reported for powders synthesized by different methods. According to the literature, on the other hand, it is expected that microwave sintering should enhance the densification of ceramics as compared to conventional method $[16,27]$. However, there is a lack of knowledge about the use of different techniques for sintering OPM powders. Therefore, to evaluate the influence of the sintering method on the final properties of PZT samples, ceramic bodies with different compositions were sintered at $1000{ }^{\circ} \mathrm{C}$ for $2 \mathrm{~h}$ using a tubular conventional oven (CO) and a commercial microwave (MW) system. Table 3 summarizes the weight loss, shrinkage and relative density of the sintered ceramic samples calculated by the Archimedes method.
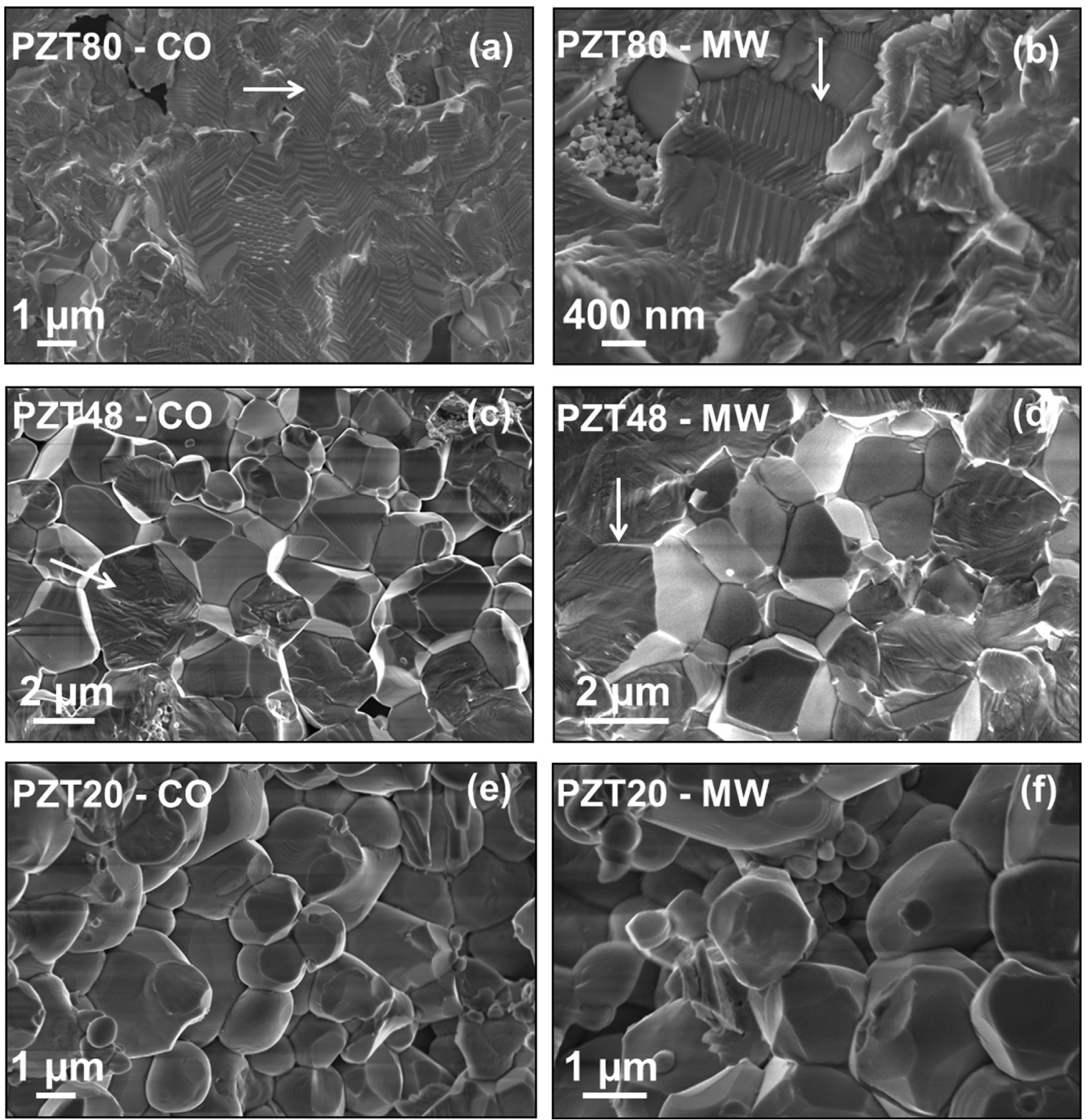

Fig. 6. FEG images of fractured PZT ceramic bodies sintered in conventional and microwave ovens. Some regions of exposed domains are indicated by white arrows. 
a

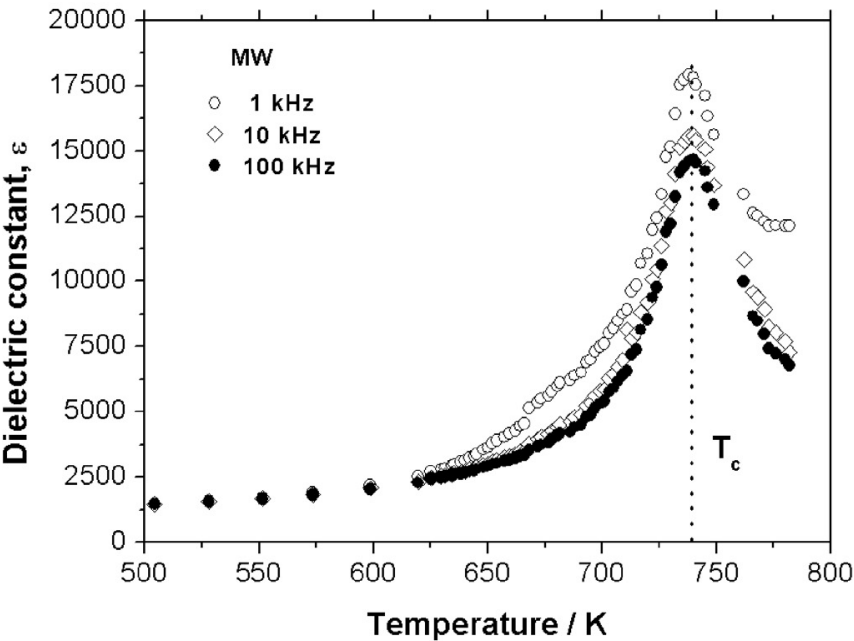

b

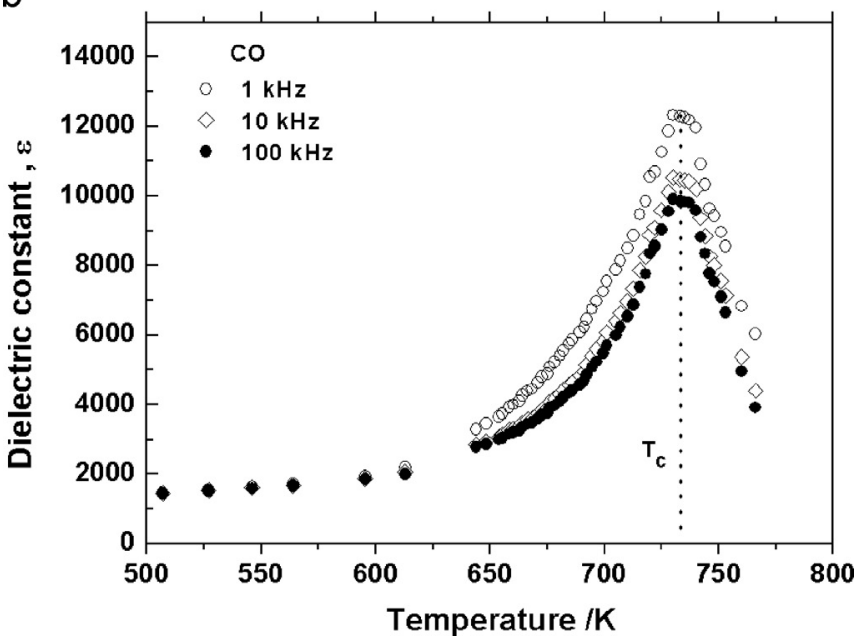

Fig. 7. Dielectric constant in function of frequency $(1,10 \mathrm{and} 100 \mathrm{~Hz})$ and temperature of PZT48 samples sintered in (a) microwave (MW) and (b) conventional (CO) ovens.

These characteristics are very important since the dielectric constant of PZT is strongly dependent on shrinkage and densification [27]. Nevertheless, the weight loss of the composition observed was smaller than $1 \%$ for all samples but, interestingly, only the MBP sample showed densities higher than 99\% whereas the samples PZT80 and PZT20 showed high porosity. The measured shrinkage was also higher for PZT48 than for other compositions. The XRD patterns of PZT20 ceramics in Fig. 5 show a rhombohedral structure identical to the pattern observed in Fig. 2, however, a small extra peak (indicated by an open circle) can be observed in the patterns of PZT80 near to the (101) peak, which can indicate that some lead oxide was segregated during the sintering due to volatilization. Regardless of the method used for sintering, the expected mixture of phases was observed in the patterns of a

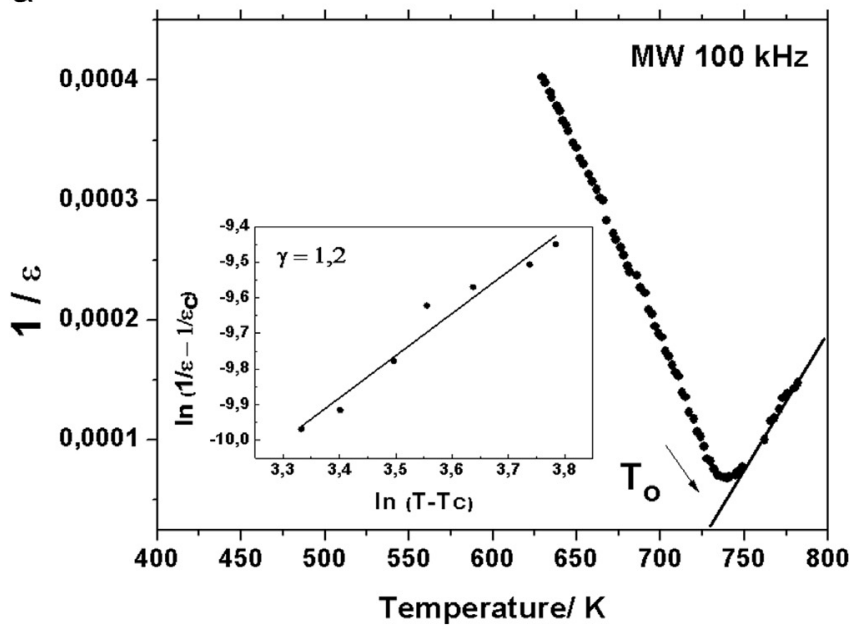

b

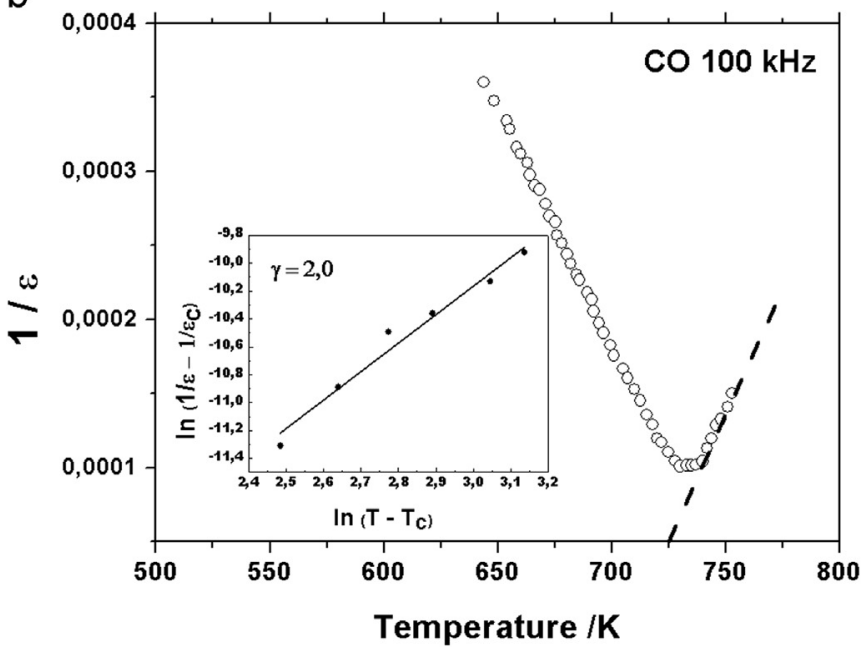

Fig. 8. The temperature behavior in function of the inverse of dielectric constant of (a) microwave (MW) and (b) conventional (CO) sintered PZT48 samples at $100 \mathrm{kHz}$. Inset.

ceramics with compositions near the MPB. In addition, the chemical composition of each ceramic sample was confirmed using energy dispersive X-ray (EDX) spectroscopy. Table 4 summarizes the composition of the fractured surface of ceramics and shows that the calculated chemical composition of sintered samples are quite close to the nominal molar composition indicating that the OPM promotes the formation of materials with a high compositional homogeneity.

The morphology of fractured surfaces was examined using a FE-SEM microscope (Fig. 6), and a transgranular fracture was observed in the PZT80 image. This type of fracture occurs through the grains to release the internal stresses and exposes the ferroelectric domains formed [28,29]. Inversely, the intergranular fracture observed in the PZT20 images occurred between the

Table 5

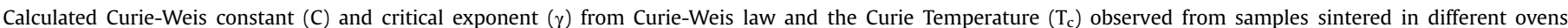
(conventional and microwave) and frequencies (1,10 and $100 \mathrm{kHz}$ ).

\begin{tabular}{|c|c|c|c|c|c|c|c|c|}
\hline \multirow[t]{2}{*}{ Frequency (kHz) } & \multicolumn{4}{|c|}{ Conventional oven } & \multicolumn{4}{|c|}{ Microwave oven } \\
\hline & C & $\gamma$ & $\varepsilon_{(\max )}$ & $\mathbf{T}_{\mathbf{c}}(\mathbf{K})$ & C & $\gamma$ & $\varepsilon_{(\max )}$ & $\mathbf{T}_{\mathrm{c}}(\mathbf{K})$ \\
\hline 1 & $2.41 \times 10^{-6}$ & 1.48 & 12,333 & 730 & $6.55 \times 10^{-7}$ & $\sim 1.00$ & 17,911 & 738 \\
\hline 10 & $3.06 \times 10^{-6}$ & 1.65 & 10,525 & 730 & $1.96 \times 10^{-6}$ & 1.54 & 15,886 & 738 \\
\hline 100 & $3.57 \times 10^{-6}$ & 2.00 & 9899 & 730 & $2.20 \times 10^{-6}$ & 1.20 & 14,684 & 738 \\
\hline
\end{tabular}


grains, which indicate a material with a homogenous morphology [29]. The PZT48 images present both types of fracture due to the coexistence of tetragonal and rhombohedral structures. In addition, these samples present a high density enhanced by the formation of a liquid phase between the grains. However, no differences were noted in the images of PZT ceramics sintered by the conventional method or MW radiation, which is in agreement with reported by Goldstein and Kravchik [30]. They observed that the densification of PZT obtained by MW method is similar to the results achieved in conventional furnaces after longer heating cycles. Further experiments must be conducted with systems synthesized by the OPM route to evaluate the influence of microwave energy in the microstructure since it is well know that this type of sintering can result in dense samples with smaller and more homogenous grains in shorter sintering times [12,31].

\subsection{Ceramic dielectric characterization}

Samples with a relative density above $90 \%$ were submitted to dielectric measurements at different frequencies (1, 10 and $100 \mathrm{kHz}$ ) as function of temperature. Unexpectedly, PZT80 samples showed a no usual capacitance behavior, and the Curie temperature could not be properly determined. It is possible that the higher tetragonality factor of PZT80 (closer to pure $\mathrm{PbTiO}_{3}$ ) affected the measurements or that the low density of samples (between $92 \%$ and $94 \%$ ) permitted the permeation of gold from the contacts though the pores. On the other hand, a normal ferroelectric behavior was observed for both PZT48 samples sintered by $\mathrm{CO}$ and MW methods, with the maximum of dielectric constant $(\varepsilon)$ close to the Curie temperature ( $\left.\mathrm{T}_{\text {Curie }}\right)$.

The dielectric constant curves of PZT48 as a function of temperature at different frequencies, with a typical ferroelectricparaelectric transition, are shown in Fig. 7(a) for samples sintered using MW and in Fig. 7(b) for samples sintered in a conventional oven (CO). The dielectric constant of the sample sintered in MW $\left(\varepsilon_{\max }=17,911\right.$ in Table 5$)$ is higher than the dielectric constant of the sample sintered in conventional oven and also higher than any other value found in the literature for this system (considering the best of our knowledge). An anomalous Curie temperature, which is much higher than the expected value of $669 \mathrm{~K}\left(396^{\circ} \mathrm{C}\right)$ [32], was observed and can be associated with the intrinsic characteristic of the materials synthesized by the OPM method and be related to the oxidant environment promoted by the use of the inorganic peroxo-complex. This environment hinders the creation of oxygen vacancies in the structure that give mobility to domain walls affecting, consequently, the sample polarization [33].

The ferroelectric-to-paraelectric transition order was determined by the Curie-Weis law in the vicinity of the transition temperature (eq.1), where $\varepsilon_{\mathrm{o}}$ is the permittivity of vacuum and $C$ is the Curie constant. It is well known that a first-order transition occurs when the Curie-Weiss temperature $\left(T_{0}\right)$ is smaller than the transition temperature $\left(\mathrm{T}_{\mathrm{C}}\right)$ and, on the other hand, a second-order transition is observed when $T_{o}=T_{C}$.

$\varepsilon=\varepsilon_{0}+C /\left(T_{0}-T_{C}\right)$

Fig. 8 shows the dependence of the temperature with the inverse of the dielectric constant at $100 \mathrm{kHz}$ for PZT48 samples sintered in (a) MW and (b) CO ovens. When the dielectric stiffness was fitted at a narrow temperature range near to the phase transition, the calculated Curie-Weiss temperature found was lower than the Curie temperature (Table 5), which indicates a first-order transition [34]. The inset of Fig. 8 was obtained from the empirical relationship that describes the diffuseness of the phase transition represented by the critical exponent $\gamma$ (Eq. 2), where $\varepsilon_{\mathrm{c}}$ is the dielectric constant at phase transition temperature $\left(\mathrm{T}_{\mathrm{C}}\right)$. $\ln \left[(1 / \varepsilon)-\left(1 / \varepsilon_{0}\right)=\gamma \cdot \ln \left(T-T_{C}\right)\right.$

The $\gamma$ exponent is equal to unity for a sharp transition and it lies in the range $1<\gamma \leq 2$ when a diffuse transition is characterized [34]. The results from this empirical relationship (Table 5) suggest that the ferroelectric-paraelectric phase transition is relatively diffuse. Camargo et al. [26] reported a similar behavior as observed in this work for PZT with a 50/50 ratio, which supports the reproducibility of materials produced by the OPM route.

\section{Conclusions}

Highly reactive PZT powders with different compositions were successfully synthesized by the OPM method and were used to prepare dense ceramic bodies, which demonstrate the versatility of the OPM route in the preparation of PZT with different compositions. These samples were sintered at $1000{ }^{\circ} \mathrm{C}$ for $2 \mathrm{~h}$ using a tubular CO and a MW system and showed a relatively diffuse ferroelectric-paraelectric phase transition regardless of the sintering method. The calculated dielectric constant of samples with compositions near the MPB sintered by MW system (17.911) was higher than the dielectric constant of samples sintered using a CO oven (12.333) with an anomalous high Curie temperature.

\section{Acknowledgements}

The financial support from FAPESP (Grants 2007/50904-2, 2009/01587-0 and 2015/13958-2), CNPq and CAPES are gratefully acknowledged. The CEPID/CDMF FAPESP (Grant 2013/07296-2) also supported this study.

\section{References}

[1] B. Noheda, Structure and high-piezoelectricity in lead oxide solid solutions, Curr. Opin. Solid State Mater. Sci. 6 (2002) 27-34.

[2] W. Qiu, H.H. Hng, Ferroelectric lead scandium tantalate from mechanical activation of mixed oxides, Mater. Chem., Phys. 75 (2002) 151-156.

[3] S.S. Chandratreya, R.M. Fulrath, J.A. Pask, Reactions mechanisms in the formation of PZT solid solutions, J. Am. Ceram. Soc. 64 (1981) 422-425.

[4] T.I. Chang J.L. Huang, H.P. Lin, S.C. Wang, H.H. Lu, L. Wu, J.F. Lin, Effect of drying temperature on structure, phase transformation of sol-gel derived lead zirconate titanate powders, J. Alloy. Compd. 414 (2006) 224-229.

[5] E.R. Camargo, M.D. Gonçalves, M. Kakihana, The oxidant peroxide method (OPM) as a new alternative for the synthesis of lead-based and bismuth-based oxides, J. Mater. Res. 29 (2014) 131-138.

[6] E.R. Camargo, M. Kakihana, Lead Hafnate $\left(\mathrm{PbHfO}_{3}\right)$ Perovskite powders synthesized by the oxidant peroxo method, J. Am. Ceram. Soc. 85 (2002) 2107-2109.

[7] E.R. Camargo, M. Kakihana, Peroxide-based route free from halides for the synthesis of lead titanate powder, Chem. Mater. 13 (2001) 1181-1184.

[8] E.R. Camargo, C.M. Barrado, C. Ribeiro, E. Longo, E.R. Leite, Nanosized lead lanthanum titanate (PLT) ceramic powders synthesized by the oxidant peroxo method, J. Alloy. Compd. 475 (2009) 817-821.

[9] L.P. Santos, E.R. Camargo, M.T. Fabbro, E. Longo, E.R. Leite, Wet-chemical synthesis of magnesium niobate nanoparticles powders, Ceram. Int. 33 (2007) 1205-1209.

[10] J.M. Calderon-Moreno, E.R. Camargo, Electron microscopy studies on the formation and evolution of sodium niobate nanoparticles from a polymeric precursor, Catal. Today 78 (2003) 539-542.

[11] A. Seal, R. Mazumder, A. Sen, H.S. Maiti, Fast firing of lead zirconate titanate ceramics at low temperature, Mater. Chem. Phys. 97 (2006) 14-18.

[12] P.K. Sharma, A. Ounaies, V.V. Varadan, V.K. Varadan, Dielectric and piezoelectric properties of microwave sintered PZT, Smart Mater. Struct. 10 (2001) $878-883$.

[13] E.R. Camargo, J. Frantti, M. Kakihana, Low temperature chemical synthesis of lead zirconate titanate (PZT) powders free from halides and organics, J. Mater. Chem. 11 (2001) 1875-1879.

[14] A.H. Pinto, F.L. Souza, A.J. Chiquito, E. Longo, E.R. Leite, E.R. Camargo, Characterization of dense lead lanthanum titanate ceramics prepared from powders synthesized by the oxidant peroxo method, Mater. Chem. Phys. 124 (2010) 1051-1056. 
[15] K. Raju, P.V. Reddy, Synthesis and characterization of microwave processed PZT material, Curr. Appl. Phys. 10 (2010) 31-35.

[16] M.V. Ramana, S.R. Kiran, N.R. Reddy, K.V. Siva Kumar, V.R.K. Murthy, B. S. Murty, Investigation and characterization of $\mathrm{Pb}\left(\mathrm{Zr}_{0.52} \mathrm{Ti}_{0.48}\right) \mathrm{O}_{3}$ nanocrystalline ferroelectric ceramics: by conventional and microwave sintering methods, Mater. Chem. Phys. 126 (2011) 295-300.

[17] V.K. Sankaranarayanan, C. Sreekumar, Precursor synthesis and microwave processing of nickel ferrite nanoparticles, Curr. Appl. Phys. 3 (2003) 205-208.

[18] E.R. Camargo, E. Longo, E.R. Leite, V.R. Mastelaro, Phase evolution of lead titanate from its amorphous precursor synthesized by the OPM wet-chemical route, J. Solid State Chem. 177 (2004) 1994-2001.

[19] A.M. Jonas, T.P. Russell, D.Y. Yoon, Synchrotron X-ray scattering studies of crystallization of poly(ether-ether-ketone) from glass and structural changes during subsequent heating-cooling processes, Macromolecules 28 (1995) 8491-8503.

[20] C.A. Randall, N. Kim, J.P. Kucera, W. Cao, T.R. Shrout, Intrinsic and extrinsic size effects in fine-grained morphotropic-phase-boundary lead zirconate titanate ceramics, J. Am. Ceram. Soc. 81 (1998) 677-688.

[21] R. Guo, L.E. Cross, S.E. Park, B. Noheda, D.E. Cox, G. Shirane, Origin of the high piezoelectric response in $\mathrm{PbZr}_{1}, \mathrm{Ti}_{x} \mathrm{O}_{3}$, Phys, Rev. Lett. 84 (2000) 5423-5426.

[22] A. Banerjee, S. Bose, Free-standing lead zirconate titanate nanoparticles: lowtemperature synthesis and densification, Chem. Mater. 5610 (2004) 5610-5615.

[23] G. Gasparotto, A.Z. Simões, M.A. Zaghete, L. Perazolli, J.A. Varela, E. Longo, Synthesis and characterization of barium-doped PZT ceramics, Ceramica 49 (2003) 110-115.
[24] S.F. Wang, Y.R. Wang, T. Mahalingam, J.P. Chu, K.U. Lin, Characterization of hydrothermally synthesized lead zirconate titanate (PZT) ceramics, Mater. Chem. Phys. 87 (2004) 53-58.

[25] S. Bose, A. Banerjee, Novel synthesis route to make nanocrystalline lead zirconate titanate powder, J. Am. Ceram. Soc. 87 (2004) 487-489.

[26] E.R. Camargo, F.L. Souza, E.R. Leite, M. Kakihana, Structural and electrical characterization of dense lead zirconate titanate ceramics synthesized by the oxidant-peroxo wet-chemical route, J. Appl. Phys. 96 (2004) 2169-2172.

[27] Y.T. Chen, C.I. Sheu, S.C. Lin, S.Y. Cheng, Effects of microwave heating on dielectric and piezoelectric properties of PZT ceramics tapes, Ceram. Int. 34 (2008) 621-624.

[28] O. Guillon, F. Thiebaud, D. Perreux, Tensile fracture of soft and hard PZT, Int. J. Fract. 117 (2002) 235-246.

[29] C. Galassi, E. Roncari, C. Capiani, F. Craciun, Processing and characterization of high $Q_{m}$ ferroelectric ceramics, J. Eur. Ceram. Soc. 19 (1999) 1237-1241.

[30] A. Goldstein, M. Kravchik, Sintering of PZT powders in MW furnace at 2.45 GHz, J. Eur. Ceram. Soc 19 (1999) 989-992.

[31] D.E. Clark, W.H. Sutton, Microwave processing of materials, Annu. Rev. Mater Sci. 26 (1996) 299-331.

[32] B. Jaffe, W.R. Cook, H. Jaffe, Piezoelectric Ceramics, v. 3, first ed., Academic Press Inc., London, 1971.

[33] J.F. Scott, M. Dawber, Oxygen-vacancy ordering as a fatigue mechanism in perovskite ferroelectrics, Appl. Phys. Lett. 76 (2000) 3801-3803.

[34] B.P. Pokharel, D. Pandey, Dielectric studies of phases transitions in $\left(\mathrm{Pb}_{1-\mathrm{x}} \mathrm{Ba}_{\mathrm{x}}\right) \mathrm{ZrO}_{3}$, J. Appl. Phys. 88 (2000) 5364-5373. 